\title{
Cohesive Device Analysis in Humor
}

\author{
Wei Liu \\ Economy and Management Department, Shanghai Technical Institute of Electronic and Information \\ Shanghai, China, 201411 \\ Email: sdlw1972@sina.com
}

\begin{abstract}
Humor is popular among us. While we are familiar with humor in our daily conversation, this paper studies the humor in cohesive devices. Humor produced by speakers can arouse the audience to response with special effect. Therefore in humor a lot of cohesive devices are employed.
\end{abstract}

Index Terms-cohesive device, humor, cohesion, cultural background

\section{INTRODUCTION}

As we all know, humor is a taste of knowingness about life. Understanding humor and analyzing humor with cohesion is new to most of us. Cohesion is the network of lexical, grammatical, and other relations which provide links between various parts of a text ${ }^{1}$. Humour is a text which can stimulate special emotion of listeners or readers. The theoretical terms for the linguistics resources which link one part of a text with another are what Halliday and Hasan regard as; reference, substitution and ellipsis, conjunction, and lexical cohesion ${ }^{2}$ (Halliday and Hasan, 1985: 48).

Humour is a dynamic system of elements and colligations in the process of creating and experiencing positive sentimental polarity through secondary, emotional and artistic colligations, mainly in the area of interpersonal relationships, generally between a human being and his environment.

\section{IMPLICATION OF HUMOR}

\section{A. Various Definitions of Humor}

"The best definition of humor is: Humor may be defined as the kindly contemplation of the incongruities of life, and the artistic expression thereof. I think this is the best because I wrote it myself." -Stephen B. Leacock

"Quality of being funny" (amusing, comical)—Collins English Dictionary

"Humor is communication (written, verbal, drawn or otherwise displayed) including teasing, jokes, witticisms, satire, sarcasm, cartoons, puns, clowning, which induces (or is intended to induce) amusement, with or without laughing or smiling."

\section{B. Function of Humor}

Origin of the word "humor": Latin: "humorem: which means moisture. When the flow of the four Hypocratean humors (phlegm, blood, choler and bile) was normal, a person was said to be "in good humor"

Anyway the humor brings us happiness and health in the following aspects:

Lifts our spirits and energy level

Replenishes us from compassion fatigue

A perfect antidote for stress:

Stimulates the immune system, offsetting the immunosuppressive effects of stress

Helps to avoid burnout

Can be an empowerment tool

Gives us a different perspective on our problems, and with an attitude of detachment, we feel a sense of self-protection and control in our environment.

"If you can laugh at it, you can survive it."

- Bill Cosby

Integrates and balances activity in both hemispheres of the brain, as it involves the whole brain.

A sense of humor is a natural human attribute that is evinced in various ways, mainly as an aptitude for:

a) perceiving, understanding and reacting to humor that exists or just originates outside of us without our active participation

b) creating humor, showing and realizing original creative activity that may or may not have professional character

c) accepting humor targeted against ourselves and reacting to it with adequate humour or understanding, without being injured

d) addressing and giving humor targeted against someone else which is a reciprocal value of an ability to accept humor but demands some bold character differences

So from above-mentioned, we should first understand the humor and then we can appreciate the humor and make a 
good use of the humor. For example,

A woman imperiously demanded a colonel's commission for her son. "Sir," she told Lincoln, "My grandfather fought at Lexington, my father fought at New Orleans, and my husband was killed at Monterey." "I guess, madam," said Lincoln, " your family has done enough for the country. It's time to give somebody else a chance." Lincoln's words are humorous and his words contain funny and praise. Humorous language not only displays the language skills but also contains cohesive devices in humor.

\section{COHESIVE Devices IN HuMOR}

The concept of cohesion is a semantic one; it refers to relations of meaning that exist within the text, and that define it as a text.

\section{A. Various Devices}

Cohesion occurs where the interpretation of some element in the discourse is dependent on that of another. The one presupposes the other, in the sense that it cannot be effectively decoded except by recourse to it. When this happens, a relation of cohesion is set up, and the two elements, the presupposing and the presupposed, are thereby at least potentially integrated into a text, meanwhile, cohesion is part of the system of a language. The potential for cohesion lies in the systematic resources of reference, ellipsis and so on that are built into the language itself. The actualization of cohesion in any given instance, however, depends not merely on the selection of some option from within these resources, but also on the presence of some other element which resolves the presupposition that this sets up.

a) Reference is very important and useful in humor.

Reference is regarded by Halliday and Hasan as:

.. the specific nature of the information that is signalled for retrieval. In the case of reference the information to be retrieved is the referential meaning, the identity of the particular thing or class of things that is being referred to; and the cohesion lies in the continuity of reference, whereby the same thing enters into the discourse a second time. Signals for retrieval in a text may consist of personal pronouns, deictics, and comparatives ${ }^{4}$ (Caldas-Coulthard, 2000b: 5). These signals can refer to the context of the situation (exophorically) or entities mentioned within a text (endophorically) ${ }^{5}$ (Eggins, 1994). For example,

A: who is that talkative woman over there?

B: my wife.

C: it's my mistake.

D: no, it's mine.

The personal reference offered us humorous meaning and avoid pointing the person directly.

Another example,

The man in the prison asked a new comer why he was sent there. The new comer answered, "I am out of luck, I think. A few days ago I was walking in the street when I saw a piece of dirty rope. I thought nobody wanted it so I picked it up and took it home." "But it is not against the law to pick up a piece of rope and take home!" "I told you I had bad luck, didn't notice there was an ox at the other end of that rope."

May be the other end of the rope is too long to be seen or this is a wonderful excuse!

b) Substitution is often used in humor.

Substitution is a relation in the wording rather than in the meaning. It has been emphasized already that the classification of cohesive relations into different types should not be seen as implying a rigid division into watertight compartments. Substitute is a sort of counter which is used in place of the repetition of a particular item. For example,

Customer: Waiter, my lobster is without a claw. How is that?

Waiter: Well, sir, they are so fresh that they fight with each other in the kitchen.

Customer: Take this one away, and bring me one of the winners.

The first one refers to the lobster without claw; the second one means the lobster with claw. Whereas in reference there is no implication that the presupposed item could itself have figured in the text, and in many instances we know it could not have done, this is implied in the case of substitution.

Since substitution is a grammatical relation, a relation in the wording rather than in the meaning, the different types of substitution are defined grammatically rather than semantically. The criterion is the grammatical function of the substitute item. In English, the substitute may function as a noun, as a verb, or as a clause.

c) Ellipsis usually takes place in humor.

We often regard the ellipsis as the zero of substitution. When we talk of ellipsis, we are not referring to any and every instance in which there is some information that the speaker has to supply from his own evidence. That would apply to practically every sentence that is ever spoken or written, and would be of no help in explaining the nature of a text. We are referring specifically to sentences, clauses, etc whose structure is such as to presuppose some preceding item, which then serves as the source of the missing information. An elliptical item is one which, as it were, leaves specific structural slots to be filled from elsewhere. This is exactly the same as presupposition by substitution, except that in substitution an explicit 'counter' is used, eg: one or do, as place-marker for what is presupposed, whereas in ellipsis nothing is inserted into the slot. That is why we say that ellipsis can be regarded as substitution by zero. For example, 
'and how many hours a day did you do lessons?' said Alice, in a hurry to change the subject.

'ten hours the first day, 'said the Mock Turtle: 'nine the next, and so on.'

The nominal group nine is presupposing, meaning nine hours, and so is the next, meaning the next day. The two clauses nine the next and ten hours the first day are also both presupposing, representing we did lessons ten hours the first day, etc. For example,

When the man and his wife returned to their seats in the dark auditorium after intermission he asked the fellow seated on the aisle, "Did someone step on your foot a little while age?"

"Yes, you did," he replied, expecting an apology.

"Ok, honey," the man said to his wife, "this is our row."

Another example:

A math teacher had been teaching his class all about fractions for the past week, and now he wanted to find out how much they had been able to remember, so he asked one of the boys in class, "If I cut a piece of meat into two pieces, what would I get?"

"Halves," answered the student at once.

"Good," said the teacher. "And if I cut each piece in half again?"

"Fourths," answered the next student.

"Eighths," answered Robert.

"Yes," said the teacher, nodding to the next boy. "And again?"

"Sixteenths, sir", was the answer.

"Good," said the teacher. "And once more, Lisa?"

"Thirty-seconds," answered Lisa after thinking for a few seconds.

"Yes, that's right. And again?" the teacher continued.

"Hamburger meat," answered the last student, who thought that all of these questions were becoming a little silly.

Many sentences in this humorous conversation are condensed to a word or a phrase, which doesn't harm the meaning and funny in the conversation.

d) Inference in humor is the most important link for us to understand and get across the meaning.

In humor much of the data presented is of the type that has generally been treated as requiring inferences on the reader's part to arrive at an interpretation. The rather general notion of inference appealed to is used to describe that process which the reader(hearer) must go through to get from the literal meaning of what is written(or said) to what the writer(speaker) intended to convey. For example, the general view of the interpretation of an utterance such as the following example - used to convey an indirect request — is that the hearer works from the literal meaning to a meaning like via inferences of what the speaker intended to convey. The following is a good illustration.

A man finds a bottle on the beach. He uncorks it and releases a genie. "Than you, and now you get three wishes because you feed me," said the genie. "Great", the man replies. "First, I want one million dollars." Poof! There is flash and a paper with Swiss bank account numbers appears in the man's hand. "Next, I want a Ferrari car." Poof! Another flash, and a new red Ferrari car is parked next to the man. "Finally," says the man, "I want to be irresistible to women." Poof! There is another blinding flash, and the man turns into a box of chocolates.

After reading the humorous story, you may ask why the genie changed the man who saved him into a box of chocolates. In fact, inference plays an important role in the story. Chocolate is popular and irresistible among the women, as we know, the man want to be irresistible and popular. So the genie understood the meaning from the man according to normal inference of natural law. In the process of inference, the cultural background and customs and habits should be essential to understand the humor. The information is the story can be seen, in formal terms, as missing link which is required to make an explicit connection between the man's requirement and the genie's offer. It is possible to think of an inference as a process of filling in the missing links between two unrelated things. Indeed, there are many examples in the literature concerning definite descriptions which we could treat in terms of the 'missing link' phenomenon.

Sanford \& Garrod's proposal that automatic connections are made between elements in a text via pre-existing knowledge representations could be used as a basis for deciding which missing links are, and which are not, likely to be inferences. For example,

During World War Two, a lot of young women in Britain were in the army. Joan Phillips was one of them. She worked in a big camp, and of course met a lot of men, officers and soldiers. One evening she met Captain Humphreys at a dance. He said to her, 'I'm going abroad tomorrow, but I'd be very happy if we could write to each other.'Joan agreed, and they wrote for several months. Then his letters stopped, but she received one from another officer, telling her that he had been wounded and was in a certain army hospital in England. Joan went there and said to the matron, 'I've come to visit Captain Humphreys.' 'Only relatives are allowed to visit patients here.' The matron said. "Oh, that's all right". answered Joan. "I'm his sister." "I'm very pleased to meet you." The matron said. "I'm his mother!"

The idea of 'automatic connections' can also be usefully applied to an aspect of text understanding which has been discussed in terms of 'informational inferences'. The mother in the story should know how many children she has, so the girl's white lie is obvious.

e) Polysemy and homonymy are the triggers leading to the humor. 
Now let's look at the example in the following.

A man approaches a pretty girl and says to her "May I hold your hand?" The girl replies "It is not heavy. I can hold it myself!"

How clever the girl is! The refusal is reasonable and humorous, which embarrassed the man. The word hold has more than one meaning. It can be understood catch or carry.

What is the correct definition of polysemy?

I don't quite understand what "words with several different, yet related meanings" is all about...which takes place usually in our daily life.

Polysemy means 'multiple meanings'. A knife that has been honed is sharp. A mind that has been trained to think through things and be incisive and not muddled is also said to be "sharp". A person who speaks incisively, directly, and abruptly is "sharp tongued'. A word then is polysemous if it has two or more extended meanings whose extensions differ somewhat but which clearly share a common semantic core.

A better word for homonymy is homophony. Homophonous words have identical sounds but entirely different meanings, not sharing a core of the same meaning. English meat and meet are homophonous. English bank the side of a river and bank where you keep and /or borrow money are examples of homophony or homonymy. For example, I go to the bank. Without context we don't know the exact meaning I go to the bank of river or I go to the bank for drawing money.

\section{B. Ambiguity Often Takes Place in Humor.}

When someone fails to understand the meaning of a word in context, then the word is being used ambiguously. Words are not ambiguous because they are polysemes, homographs, or homophones. For example bow (bau), as a polyseme, can mean a head gesture, submission, crushing, or ushering in. Normally, in context, one's intention when using this word is quite unambiguous. Even more clearly, when speech is involved, the distinction between bow (bau) to gesture, and bow (bo) -- as in rainbow or bow and arrow -- is well understood. Thus ambiguity need not arise just because words are homonyms or polysemes.

\section{CONCLUSION}

Cohesive device is often used in our daily life and all kinds of articles which bring us into different context and different understanding. Last, I would like to point out that in much, even most, humor, there are likely to be several lines of tension-building and tension-relief operating simultaneously and consequentially. A simple joke, for example, may include several incongruities, poke fun at "adult" social conventions, play with linguistic conventions and double-meanings, introduce taboo sexual topics, toy with socially unacceptable aggressiveness, establish a degree of superiority, be told by someone taking the comic role, and reveal universals of human nature all at the same time. Add such "external" factors as setting, mood, contagion, etc., and analysis becomes even more challenging. Humor reminds me of cooking, in that we have been doing it so long that even a "simple" dish involves many ingredients and complex preparations.

\section{REFERENCES}

[1] Baker, M. (1992) In Other Words: A Coursebook on Translation. London: Routledge, 180

[2] Hallday, M.A.K. \& Hasan R. (1985) Language, Context, and Text: Aspects of Language in a Social-Semiotic Perspective. Geelon, Vic.: Deakin University Press, 48

[3] Hallday, M.A.K. \& Hasan R. (1976) Cohesion in English. London: Longman Group Limited,31

[4] Eggins, S. (1994) An Introduction to Functional Linguistics. London: Pinter Publishers.

[5] Caldas-Coulthard (2000b) Written Discourse. Birmingham: The University of Birmingham,5 